\title{
Socio-economic Inequalities in the Americas-A Mitigating Educational Approach
}

\author{
Alberto Ciferri ${ }^{1}$ \\ ${ }^{1}$ Jepa-Limmat Foundation, Zurich, Switzerland \\ Correspondence: Alberto Ciferri, Jepa-Limmat Foundation, Zurich, Switzerland. Email: Alberto.Cferri@duke \\ edu
}

Received: September 25, 2018

Accepted: October 25, 2018

Online Published: November 6, 2018

doi:10.20849/jed.v2i3.501

URL: https://doi.org/10.20849/jed.v2i3.501

\begin{abstract}
A long-range educational approach aiming to mitigate the social and economic inequalities in the Americas is presented. The approach is based on a history book that emphasizes the socio-economic evolution in 28 countries of the American Continent. The book is currently used for courses in pilot schools in Central America and its extension is planned to leading institutions in North America. A phenomenological framework facilitates the identification of novel strategies for the harmonization of different ethnic groups and economic development.
\end{abstract}

Keywords: ethnic compatibility, migrations, capitalism excesses, traditions and innovations, social harmony, social conflicts, GDP, development strategies

\section{Introduction}

Striking social and economic conflicts occurs within and among the nations of the American continent. In the USA, specialized institutions tackle the most significant advances in human knowledge in spite of the occurrence of ethnic groups still living in restricted areas. In Nicaragua, the genuine interest to support independence from foreign imperialism resulted in an unending struggle. In Peru, the Andean civilization suffered centuries of repression, but it is slowly recovering a primary role in the growth of the Country. Migration patterns in the Americas and other part of the world are escalating, but the sustainability of the process is difficult to control. Recurrent socio-economic conflicts are also reported between societies poor in material resources that exhibit remarkable degree of happiness and social relationships and advanced societies rich in resources that suffer by excessive materialism.

Considering that social harmony and economic welfare are ranked among the top factors that determine happiness (with the first prevailing over the second), sociologists, economists and politicians have been extensively discussing issues related to social conflicts and the negative effects of uncontrolled economic expansion. A variety of measures has been suggested to correct the differences outlined above. Nevertheless, the incidence of social conflicts and the spread of economic differences between developed and developing countries is not abiding.

Systemic changes appear needed to resolve the above issues. Here we highlight a recently proposed educational approach based on stimulating the awareness of young generations on socio-economic issues.

\section{The Book (see Note 1)}

The first step on the above approach has been the elaboration of a history book that highlights the socio-economic evolution of 28 countries in the American continent. The 28 chapters are written by professional historians and scientists familiars with the regions they describe. Concepts of history, economy and sociology are presented in a simple and readable form allowing the book to be directed to an audience of educated individuals and students.

The book has the legitimate character of a history book. However, its focus is on social conflicts (ethnic and class) and the balance between social harmony and economic development. Several chapters deal with the native populations of America. Due to its ample horizon, the book does not include elaborate interpretations of historical events or social conflicts. However, it evidences correlations and analogies that allow the reader to appreciate the origin of recurrent problems, and formulate own ideas on possible remedies. Examples of correlations regarding the compatibility of different cultures and the impact of economic development are 
highlighted below.

\subsection{Ethnic Issues}

The book highlights ethnic issues in the cases of migrants of first generation, successive generations and established multi-ethnic nations. The book uses the "compatibility" concept (borrowed from material science) to describe three different levels of cultural interaction: full compatibility, incompatibility and "induced compatibility". The latter is based on interests shared by the migrant and the hosting populations (Henderson, 2011). It corresponds to the current concept of "sustainable migration" according to which suitable agencies ought to control migration on the basis of the needs and aspiration of newcomers and established residents (United Nations, 2018). The book emphasizes that in addition to common interests, appreciation and tolerance for the characteristics of ethnic identities need to be promoted to favor social integration, particularly for first and second generation migrants (Colombia, Mexico).

During successive generations, some of the cultural features of the migrants will be shared within the evolving multi-ethnic culture of the hosting country. In the long range, a "dominant character" of the evolving national identity will prevail (USA, Chile, Brazil ...). Predictions in the very long range are difficult to make. The concept of America as a melting pot of different cultures able to pacifically coexist might represent a model for the unified society of the future. The book hints to the possibility, in the distant future, of a more egalitarian society due to global miscegenation, resulting from increasing migrations and mixed marriages (Paraguay, Casal 2016). Puerto Rico and French Guiana offer interesting examples of political and economic integration of a developing country within the former colonial power.

Multi-ethnic nations. Several American nations have formally recognized and sustained ethnic groups and their right to implement their own traditions and languages. Several strategies were discussed to allow for a constructive blending of different ethnicities occurring in long established multi-ethnic countries. The best-known case is that of Bolivia where an emended constitution proposed in 2009 by the indigenous president Evo Morales recognized 36 ethnic groups as nations within the Bolivian State. Morales' three terms government has produced stability and economic growth although his recent siding with Venezuela and China is arousing concern over his political vision (Faundes, 2016). Territorial separation of different ethnicities appeared a viable solution for the preservation of the specific traditions and languages of the 36 nations. However, in the context of a large nation, constructive interaction between large ethnic groups should be primarily promoted. The revival of the Andean civilization in Peru, mentioned above, was not achieved by territorial separation but rather by a process of permeation of the Andean culture in the urban society (Vietor., D’Alessio \& Pino, 2016).

\subsection{Class Issues}

The book emphasizes the conflicts between the ideologies of conservatives and liberal classes. Alimented by extremism, these contrasts have led to armed conflicts and ensuing tragedies for the populations. The not yet ending struggle of Nicaragua, mentioned above, reveals that the radical support of Sandino for the rights and identity of the peasants sparked a sequence of hard dictatorship, repeated foreign invasions, a revolution, a counter-revolution and an a still unsettled society.

The recent history of Honduras and Nicaragua suggests that the constructive functioning of a nation requires not only the alternation of conservative and liberal parties, but also cultural visions that should be neither too close nor extremely different (Anguilara, 2014). It is not irrelevant to note that countries such as Canada, USA, Costa Rica and Chile, which experienced a reduced occurrence of internal conflicts, are those that produced stronger economies, even if not successful in resolving problems associated to social conflicts.

Armed conflicts may sometime be necessary to promote social change, but alternative solutions based on rationality and tolerance have often been adopted to achieve common interests. The Justice Studies Center of the Americas $(C E J A)$ has produced an interesting study that recognizes the significance of popular discontent and evidences that the proper administration of justice can manage and resolve a large number of social conflicts (Binder, 2011). Justice is indeed an essential component of democracy and of the socio-economic development of the countries.

The students using the book will appreciate that the ultimate solution to class conflict will be a cultural evolution toward the appreciation of justice, tolerance and rationality.

\subsection{Social Issues and Economic Development}

Economic development is often in conflict with traditional values. In spite of the outstanding achievements of the capitalistic and free-market system inspired by the Anglo-American culture, the problems associated with the excesses of the system mitigate its achievements. Conflicts are increasing between groups with religious 
inspiration that do not accept the materialism and related aspects of the Anglo-American culture. Other problems are related to the stability of families, the isolation of the elderly, consumerism and the excessive emphasis of governments and industries on increasing the GDP. The current emphasis on digital technologies and artificial intelligence is causing the disappearance of a growing number of activities, an increase in unemployment and perplexities for the future of humanity (Bostrom, 2015). The promoters of such innovations affirm that the flexibility of the human being will create adjustments in the form of new jobs or cultural innovations. Yet, preoccupations are growing due to the never-ending succession of innovations, their globalization, the exacerbation of inequality, the confusion between the know-how produced by a useful technology and the know-why that derives from true cultural progress.

Capitalism is good, but human greed needs to be redirected. Its real control is not well achieved by taxations and regulations but might be achieved by the recovery of a more humanistic culture. New development models should attempt to balance innovations with the basic culture of the society. The reduction of the emphasis on profit will cause a reduction of GDP, which might be compensated by an improved wealth distribution and the harmony of man with himself and with others.

A new development economy is indeed gaining strength (Shank, 2018; Martorano, 2017). Traditional agricultural and handicraft activities are rejuvenating, social enterprises are increasing, notably in Costa Rica and Paraguay, the protection of the ecosystem and renewable energies are expanding, and courses on development economics are offered by major universities. New indicators including both GDP and social harmony parameters have been proposed (Shank, 2015). The book concludes that traditional values, such as family ties, friendship and religion, are based on a fundamental need of man, "not to feel alone" that innovations will never replace.

\section{The Course}

The book highlights problems but does not directly contribute to their solution. On the other hand, the socio-economic gap between developed and developing countries is increasing. A society rich in material resources is concentrating even more in technological innovations, losing contact with human and traditional values. Diversely, a society rich in social interaction is becoming excessively polarized on family togetherness, losing contact with essential progress. Measures should be taken in both developed and developing countries to avoid serious setbacks, but the difficulty of promoting feasible changes by the establishment is evident.

A course based on the book has therefore been designed to stimulate new models of development. The minimum objective of the course is to enhance a history-based socio-economic culture. A most ambitious objective is to stimulate students' interest in considering new models of development. Greater participation of the students will be encouraged, with the aim to control and possibly reduce the socio-economic gaps among the American nations.

Students will be encouraged to propose tentative models of development for their country. The viability of such projects will not be an essential requirement. The most important achievement would be the education of new generations able to seek a better balance between traditions and innovations, based on a solid historical perspective. The course is currently offered in Central America (Guatemala) with planned extension to South and North American and European schools. It will be offered to students of every faculty (humanistic, scientific, technical) attending the last year of high school or first year of university. The principals of selected private and public schools, and their corresponding ministerial managers, are invited to consider the adoption of the course in an integral form, or modulate it with existing compatible classes.

\subsection{Material for the Course}

The students will be involved in elaborations of the chapters of the book using the correlations between events in different countries highlighted in the preceding section. They will need to elaborate parameters describing social harmony and wealth distribution. As a guideline for such an effort they rely on a phenomenological framework we have recently developed, which has some similarities with the approaches used by sociologists to describe the parameters of happiness (Pankaj \& Dorji, 2004). We define a parameter $\mathbf{F}$ related to the (extensive) quantity of social interaction, and a parameter $\mathbf{G}$ related to the extent of economic activities. A common dimensional unit is assumed ((Pankaj \& Dorji, 2004). We do not attempt to define and quantitatively asses the complex variables affecting $\mathbf{F}$ and $\mathbf{G}$. Important information may be gathered by appreciating the significance of the ratio $\mathbf{F} / \mathbf{G}$. We postulate that in a balanced society (regarded as a "reference state") equal weights should be given to social harmony and economical welfare. The postulate can be expressed as:

$$
\mathbf{F} / \mathbf{G} \sim 1 \text { (balanced society) }
$$

It follows that in a society where social interaction $(\mathbf{F})$ is large and GDP $(\mathbf{G})$ is small (e.g., Guatemala): 


$$
\mathbf{F} / \mathbf{G}>>1
$$

and in a society where $\mathbf{F}$ is small and $\mathbf{G}$ is large (e.g., USA):

$$
\mathbf{F} / \mathbf{G}<<1
$$

F/G represents the socio-economic gap between any country and the reference state. The spread between the two above values of $\mathbf{F} / \mathbf{G}$ could be used to evaluate the socio-economic gap between the corresponding nations. The analysis and control of the gaps is the main objective of the projects elaborated by our students and, indeed, one of the main problems affecting the socio-economic balance in the Americas.

The simple relationships indicated above allow considerable latitude in the general strategies to be considered for specific countries. In Guatemala, for instance, the $\mathbf{F} / \mathbf{G}$ ratio could be reduced by lowering $\mathbf{F}$ (e.g., softening family ties through migration or job mobility), or by independently increasing $\mathbf{G}$ by promotion of economic activities.

The selection of most suitable strategies may be further aided by the fact that $\mathbf{G}$ and $\mathbf{F}$ are often inversely related (e.g., job mobility reduces $\mathbf{F}$, but consequently induces an increase of $\mathbf{G}$ ). This situation allows for the possibility of altering one parameter through alteration of the other one, suggesting a most interesting strategy when direct alterations of specific parameters are not easily performed.

In the case of the USA, for example, the skyrocketing profit economy is catching the mind of a large component of the adult and young population, reducing hopes that the $\mathbf{F} / \mathbf{G}$ ratio could be increased by models aiming to reduce the $\mathbf{G}$ value. In this case, educational models, possibly based on the voices of many humanists, artists, immigrants, could contribute to an increase of $\mathbf{F}$, thus indirectly promoting an otherwise difficult to achieve decrease of $\mathbf{G}$.

Alternatively, an increase of the (intensive) quality of social interaction leaves the $\mathbf{F}$ parameter unchanged (e.g., promoting cooperation, punctuality, responsibility), but economic activities may be enhanced, inducing an increase of $\mathbf{G}$. The latter example evidences the important role that education might have on the simultaneous development of social harmony and economic activities.

\subsection{Propaedeutic Material}

The students need to be familiar with some of the basic concepts thought in standard Sociology and Economy courses. For the benefit of the students not previously exposed to these concepts, a series of lectures were designed on basic notions about culture, religion, type of governments and economy. Because of the combination of the history concepts detailed in the book with notions proper of social and economy courses, our courses have been identified as a "General Cultural Courses". A booklet describing the propaedeutic material is available. It is expected that the type of propaedeutic material will vary with form school to school. DVD copies of the whole book (Spanish edition) are made available to each student free of charge by the Foundation sponsoring the project. When necessary, the training of the teachers is also assisted by the Foundation.

\section{Further Expansion of the Project}

A similar project is tentatively considered in several nations in Africa and Asia. Potential contributors from History, Sociology and Economy Departments are invited to contact directly the author of the present article.

\section{Acknowledgment}

The support of the Jepa-Limmat Foundation is gratefully acknowledged. The Chemistry Department at Duke University offered hospitality and encouragement. The Fray Luis de la Cruz Institute, the Santa Catarina Barahona Municipal School, and the Mundo Verte School in Guatemala are currently running the course. The Cooperacióòn Española of the Spanish Embassy, the Ministry of Education of Guatemala, Cecilia Cojolon of the Asociación Jepa-Guatemala, Julio Luna of the San Carlos University, Carlos Pardo Figueroa Thays of the Catholic University of Peru, and Ernesto Paz Anguilara of the National University of Honduras offered encouragement and concrete suggestions. Alvin Crumbliss, Bill Day, Elio Soldi in Durham NC, Cinzia Bongianni and the De Ferrari Publishers in Genoa offered invaluable assistance in the elaboration of the book and the course.

\section{Note}

Note 1. The book. Spanish edition: A. Ciferri, Ed. Panorama sobre la evolucion historica y socioeconomica en las Americas. Un proyecto de desarrollo. Kindle e.book, October 2018. Non-commercial hard copies, or selected chapters, will be distributed free of charge to schools interested in establishing similar courses. Booklets 
describing propedeutic material and suggestions to the teacher aree also available. An updated commercial English edition will be available early in 2019. Contact the Foundation (md2864@mclink.it).

\section{References}

M. Binder. (2011). Resolución alternativa de conflictos. Retrieved from https://www.cejamericas.org/Documentos/DocumentosIDRC/122CEJA-INECIP.pdf

N. Bostrom. (2015). Facing the unknown: the future of humanity. Oxford University, Institute for the Future of Humanity.

J. M. Casal. (2016). From Paraguay, a history lesson on racial equality. Retrieved from http://www.globalgeopolitics.net//12/04/2016

C. Faundes. (2016). Strategic Assessment of Bolivia's Defense Policy. Retrieved from https://www.armyupress.army.mil/Portals/7/military

T. M. Henderson. (2011). A history of Mexican migration to the United States. Whiley-Blackwell.

B. Martorano. (2017). Cyclicality of Fiscal Policy in Latin America over the period 1990-2015. Review of Development Economics, 22.

P. Pankaj, \& T. Dorji. (2004). Measuring Individual Happiness in Relation to Gross National Happiness in Bhutan: Some Preliminary Results from Survey Data. Retrieved from www.bhutanstudies.org.bt/.../19.GNH\&development.pdf

E. Paz Anguilara. (2014). La diferenciación ideológica de los partidos políticos hondureños. La Tribuna 11-14 marzo 2014.

M. Shank. (2018). National indicators for a new era. Retrieved from www.michaelshank.tv/wp.../National-Indicators-for-a-New-Era

R. H. Vietor, F. A. D’Alessio, \& R. M. Pino. (2016). Peru: Economic miracle or just a mirage? Harvard Business School Case 716-028.

United Nations. (2018). About sustainable migration goals. Italian Agency for International Development. Retrieved from https://www.un.org/sustainabledevelopment/sustainable-developm

\section{Copyrights}

Copyright for this article is retained by the author(s), with first publication rights granted to the journal.

This is an open-access article distributed under the terms and conditions of the Creative Commons Attribution license (http://creativecommons.org/licenses/by/4.0/). 